\title{
Wearable Technology to Assist the Patients Infected with Novel Coronavirus (COVID-19)
}

\author{
Md. Milon Islam ${ }^{1}(1) \cdot$ Saifuddin Mahmud² ${ }^{2}$ L. J. Muhammad ${ }^{3} \cdot$ Md. Rabiul Islam $^{4} \cdot$ Sheikh Nooruddin ${ }^{1}$. \\ Safial Islam Ayon ${ }^{5}$
}

Received: 4 September 2020 / Accepted: 17 September 2020 / Published online: 1 October 2020

(c) Springer Nature Singapore Pte Ltd 2020

\begin{abstract}
Wearable technology plays a significant role in our daily life as well as in the healthcare industry. The recent coronavirus pandemic has taken the world's healthcare systems by surprise. Although trials of possible vaccines are underway, it would take a long time before the vaccines are permitted for public use. Most of the government efforts are currently geared towards preventing the spread of the coronavirus and predicting probable hot zones. The essential and healthcare workers are the most vulnerable towards coronavirus infections due to their required proximity to potential coronavirus patients. Wearable technology can potentially assist in these regards by providing real-time remote monitoring, symptoms prediction, contact tracing, etc. The goal of this paper is to discuss the different existing wearable monitoring devices (respiration rate, heart rate, temperature, and oxygen saturation) and respiratory support systems (ventilators, CPAP devices, and oxygen therapy) which are frequently used to assist the coronavirus affected people. The devices are described based on the services they provide, their working procedures as well as comparative analysis of their merits and demerits with cost. A comparative discussion with probable future trends is also drawn to select the best technology for COVID-19 infected patients. It is envisaged that wearable technology is only capable of providing initial treatment that can reduce the spread of this pandemic.
\end{abstract}

Keywords Novel coronavirus $\cdot$ COVID-19 $\cdot$ Wearable technology $\cdot$ Symptoms monitoring $\cdot$ Respiratory support

\section{Introduction}

This article is part of the topical collection "Advances in

Computational Approaches for Artificial Intelligence, Image

Processing, IoT and Cloud Applications" guest edited by Bhanu Prakash K N and M. Shivakumar.

Md. Milon Islam

milonislam@cse.kuet.ac.bd

Saifuddin Mahmud

smahmud2@kent.edu

L. J. Muhammad

lawan.jibril@fukashere.edu.ng

Md. Rabiul Islam

rabiulnewemail@gmail.com

Sheikh Nooruddin

nooruddinimad@gmail.com

Safial Islam Ayon

ayon@cse.green.edu.bd
The whole world is going through a very critical and unprecedented situation since the recognition of the novel coronavirus SARS-CoV-2 (COVID-19) [1, 2]. After the initial official reports of pneumonia of unknown cause in December 2019, it has rapidly spread throughout the world. By observing the situation, the World Health Organization (WHO) declared a public

1 Department of Computer Science and Engineering, Khulna University of Engineering \& Technology, Khulna 9203, Bangladesh

2 Department of Computer Science, Kent State University, Kent, Ohio, USA

3 Department of Mathematics and Computer Science, Faculty of Science, Federal University of Kashere, P.M.B. 0182, Gombe, Nigeria

4 Department of Electrical and Electronic Engineering, Bangladesh Army University of Engineering and Technology, Natore 6431, Bangladesh

5 Department of Computer Science and Engineering, Green University of Bangladesh, Dhaka 1207, Bangladesh 
health emergency in January and characterized it as a pandemic in March of this current year [2]. It has spread now about 216 countries, 2 international territories, and more than 25.90 million confirmed cases with 0.86 million confirmed deaths (up to September 2, 2020) [2]. The number of affected and death cases related to coronavirus is increasing rapidly.

COVID-19 affects people in different ways. Any symptoms or a set of symptoms may be present in an affected patient like fever, dry cough, fatigue, headache, loss of taste or smell, diarrhoea, aches and pain, skin rash, conjunctivitis, etc. [2-5]. However, some cases have been reported where the patients do not exhibit any symptoms. Besides this, after being infected by the virus, 5-6 days (average), or even 14 days (maximum) are required to show the symptoms [6-8]. That makes it easier to spread the virus. Healthy young people face mild to moderate respiratory illness and recover without any serious treatment. On the contrary, the elderly who were previously affected by some other complicated diseases such as heart failure or coronary artery diseases [9], diabetes [10], cancer [11-13], liver disorder [14], etc. are infected more severely.

The number of infected people around the world is increasing exponentially. Public healthcare systems are not able to cope with the increasing number of patients. The hospitals have quickly become overcrowded due to the excess number of patients but however the ventilators, personal protective equipment (PPE), oxygen supplier, etc. are inadequate. As the hospitals are not able to accommodate the influx of patients, some patients need to lay on mattresses upon the floor. The hospitals are becoming a notable carrier of coronavirus due to the constant stream of new coronavirus infected patients. The health caregivers, surgeons, hospital management personnel have the highest probability of becoming infected. As a consequence, public health experts advise taking treatment from home despite getting in touch with the hospital under normal circumstances [2]. People should not be hospitalized immediately before they show serious symptoms such as trouble in breathing, chest pain or pressure, bluish lips or face, loss of speech, etc.

The global pandemic requires a global response. The researcher, doctors, engineers are trying their best to stop totally or to reduce the danger of this pandemic $[15,16]$. As the vaccine for the novel coronavirus is still under trial, efforts should be focused on preventing the spread of the virus. In the present era of artificial intelligence (AI) [17-20], the new technologies can play a vital role to assist the world against the pandemic. Wearable technology that can collect a wide range of data such as heart rate, blood pressure, body temperature, ECG, lung sound, blood oxygen saturation $\left(\mathrm{SpO}_{2}\right)$ level, etc. may help a great extent in preventing the spread of the infectious coronavirus [21]. The healthcare system with wearable technology allows a surgeon to monitor infected or probable patients, assess the health risk, and forecast future conditions remotely $[22,23]$. During the quarantine or self-treatment period, a person/patient can be fully monitored by a doctor with the help of wearable technology. This also provides an opportunity for remote treatment and puts the healthcare workers at a lesser risk of infection. Furthermore, a study related to coronavirus transmission with skilled nursing facilities indicated that the asymptotic rate of transmission was 56\% (27 out of 57), among them, $90 \%$ shows symptoms subsequently. From this scenario, it is obvious that the symptom-based screening method may fail to detect more than $50 \%$ of people affected by COVID-19. The continuous data monitoring generated by wearable technology can overcome these challenges.

The wearable technology has to be enriched for the following reasons: (i) to monitor remotely the status of the health of a coronavirus infected patients or self-quarantined individuals who are taking treatment in a personal room. (ii) Forecasting the risk of the vulnerable people who are under the critical zone regarding COVID-19. The early screening will assist in reducing the infection rate significantly. (iii) To decrease the transmission rate of infectious COVID-19 among the surgeons, caregivers, and hospital management personnel and patients of other diseases as wearable technology allows the surgeons and caregivers to check patients in real-time. (iv) To ensure service delivery of telehealth and Internet of Medical Thing (IoMT) technologies to fight against COVID-19 as without the patient data produced by wearable technology, the telehealth system, or IoMT or any other intelligent medical system cannot perform effectively.

This paper aims to describe the impact of the relevant wearable technology that helps to fight against the pandemic COVID-19. The entire review work is categorized in two directions: (i) initial symptoms monitoring systems for COVID-19 (ii) respiratory support systems for COVID19 infected patients. All the developed systems are demonstrated in terms of types of services, working functionalities, relative cost as well as merits and demerits of the current systems. The challenges faced by existing systems as well as potential future works are also drawn.

The rest of the paper is as follows. The supportive wearable devices for assisting COVID-19 patients are reviewed in Sect. "Supportive Wearable Devices for COVID-19 Patients". Section "Discussions" discusses the reviewed systems, their limitations, and some future directions. Finally, Sect. "Conclusion" presents the concluding remarks.

\section{Supportive Wearable Devices for COVID-19 Patients}

The reviewed wearable systems for assisting the patient affected with the novel coronavirus (COVID-19) can be broadly divided into two main categories: basic symptoms monitoring systems for COVID-19 and respiratory support 
systems for COVID-19. While basic symptoms monitoring systems observe and identify potential coronavirus patients by monitoring health indicators such as respiration rate (RR), body temperature, pulse rate, oxygen saturation in the blood $\left(\mathrm{SpO}_{2}\right)$, etc., respiratory support systems such as ventilators, CPAP systems, oxygen therapy, etc. aid coronavirus infected patients on their recovery process. Figure 1 provides an overview of the wearable assistive technology for the patients infected by the novel coronavirus.

\section{Basic Symptoms Monitoring Systems for COVID-19}

The term wearable technology represents the intelligent electronic devices that are worn on the body for assessing, evaluating, and transferring different types of data. The data can be, for example, different types of signals related to the body and physical activity. The wearable technology performs a substantial role in the detection of COVID-19 symptoms to assist the patients infected by this novel virus. There are three signs which are considered as primary coronavirus symptoms: (i) respiratory distress/difficulty (ii) fever and (iii) coughing [24] which are universal to all the clinical demonstrations of COVID-19. The person who is infected by this virus has a respiratory rate $(R R) \geq 20$ breaths/min (bpm), body temperature $\geq 38{ }^{\circ} \mathrm{C}$, (iv) pulse rate $>100$ beats/ min in general $[25,26]$. Hence, it is crucial to assess respiratory, cardiovascular monitoring, and evaluation of other parameters such as body temperature, oxygen saturation $\left(\mathrm{SpO}_{2}\right)$. Using wearable sensors, the necessary assessment, monitoring, and evaluation of parameters are performed very easily, effectively, and cost-efficiently. The systems that are developed for basic signs monitoring for COVID-19 infected patients are described as follows.

\section{Respiration Rate Monitoring}

Respiration rate for respiratory assessment is one of the most crucial parameters in COVID-19 infection detection as the virus has a severe effect on the lungs area. COVID19 shows a lower-respiratory tract infection that causes disorder in lung tissue, shortness of breath, and coughing [27]. The patient who has serious respiratory difficulty has a respiration rate $\geq 30$ breaths/min that can lead to acute respiratory distress syndrome (ARDS) [28]. Real-time and continuous assessment of RR is very important for monitoring the current condition, progression, and treatment of the patients infected with COVID-19. A group of researchers has already proposed wearable devices that are mounted on the chest [29] or put on the skin [30] to measure the RR and these devices are useful for monitoring COVID-19 patients. Accelerometer-based sensors, triboelectric sensors, and wearable strain gauge sensors are used to measure the RR and provides satisfactory results. But patients may not feel comfortable wearing these types of belts. RR can be assessed by monitoring the variations in body temperature, humidity, and $\mathrm{CO}_{2}$ using wearable devices. Using the airflow-sensing method, researchers have proposed many wearable devices that used nasal or oronasal thermistor, a humidity sensor and a $\mathrm{CO}_{2}$ sensor that identifies the temperature/humidity/ $\mathrm{CO}_{2}$ changes between the inhaled and exhaled air. For instance, Liu et al. [31] proposed a RR system that is used to be placed on the upper lip which is mainly a flexible epidermal

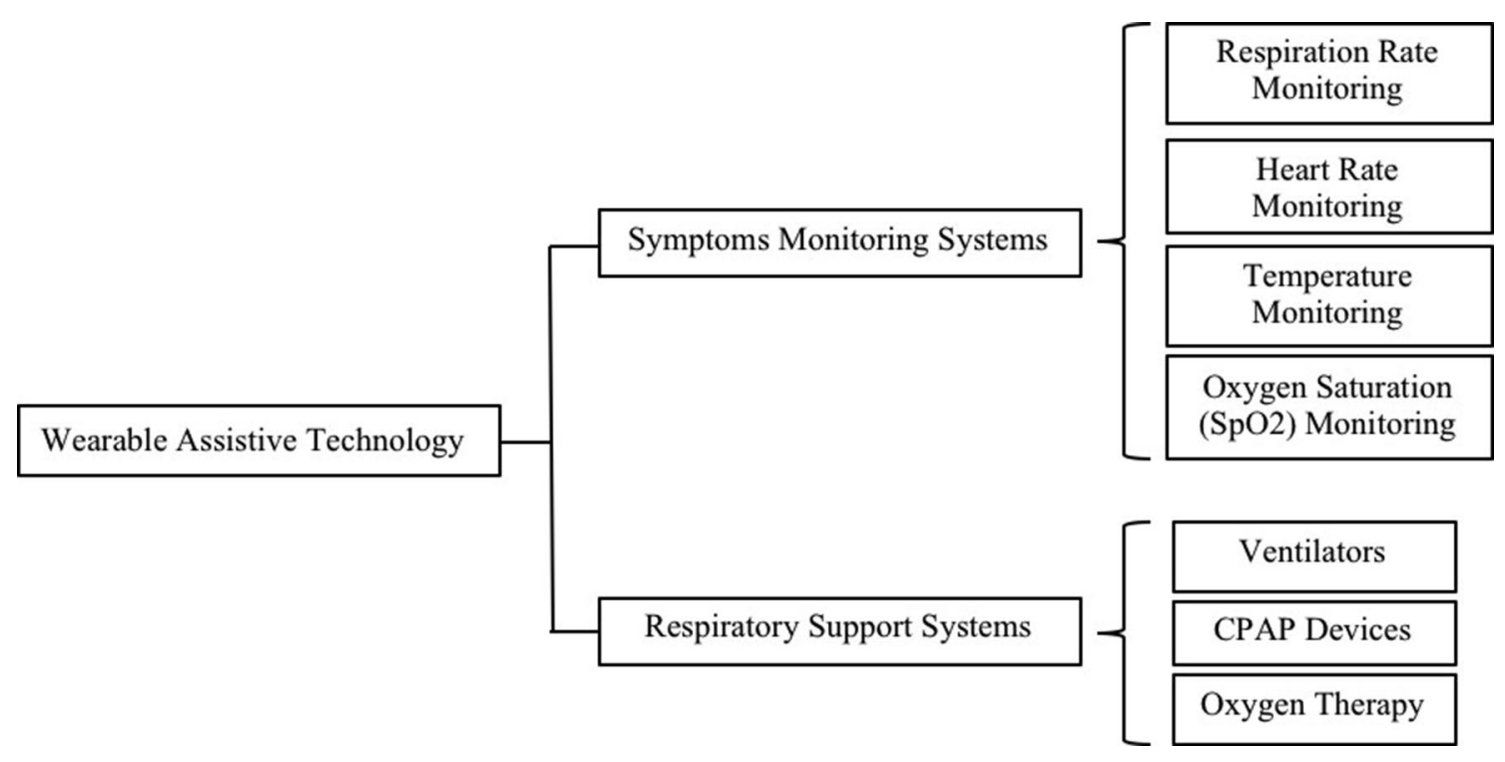

Fig. 1 Overview of the wearable assistive technology for the patients infected with COVID-19 
respiratory system based on the thermal convection. Dai et al. [32] introduced a polyelectrolyte humidity sensor, a particular type of humidity sensor that can be attached to a facial mask which is widely used during the COVID19 pandemic. But the system may not be suitable for the patients and the movement of the sensor may influence the accuracy. RR can also be measured by electrocardiography (ECG) and photoplethysmogram (PPG) which can be easily obtained by wearable devices. Charlton et al. [33] proposed a system for RR estimation from ECG and PPG [34] which increased the estimation accuracy. The benefit of the system is that it can be incorporated into commercial wearable devices, thus adding RR monitoring functionality in existing systems. Hence, this technology would be very efficient for COVID-19 patients to monitor their RR during this current pandemic situation.

\section{Heart Rate Monitoring}

COVID-19 can significantly affect heart function and lead to myocardial injury which may irreparably damage the cardiovascular system [35]. Viral illness due to the COVID-19 increases physiological stress on the body which typically manifests as an overall increase in heart rate (HR). Wearable devices are used to monitor the HR of COVID-19 patients as they are very convenient and cost-effective.

A piezoresistive sensor based wearable device for monitoring heart rate was proposed by Quy et al. [36]. The device monitors the heart rate in real-time. It is very cost-effective, small, and has high accuracy. Besides other clinical uses, this device can be used for COVID-19 patients. Shahshahani et al. [37] developed an ultrasound sensor based wearable device for heart rate monitoring. But the piezo sensor of the device is supposed to place perpendicular to the heart for achieving better accuracy. This device monitors the heart rate in real-time as well as ECG signals which is very helpful for COVID-19 patients nursing. Tamilselvi et al. [38] proposed a system for health monitoring that can monitor primary metrics of a patient such as body temperature, heart rate, eye movement, and percentage of oxygen saturation. For this purpose, the system integrated heartbeat, $\mathrm{SpO}_{2}$, temperature, and eye blink sensors for data collection and Arduino-UNO as a processing device. As this system is IoT based, doctors can monitor the COVID-19 patients remotely. Banerjee et al. [39] proposed a non-invasive technique based pulse rate detection system. The system applied the plethysmography process and consistently exhibited the result digitally in a real-time monitoring device. The device provides a reliable heart rate monitoring system for COVID-19 patients as it is better than other contemporary invasive techniques based devices.

\section{Temperature Monitoring}

Temperature measurement is exceptionally essential for COVID-19 detection and has been broadly used by many countries as an instant test to determine if travellers or citizens have been infected with COVID-19. While quarantining people with fever may prevent spread to some point, this method for body temperature monitoring is not adequate as COVID-19 can be spread before the fever grows. The continuous monitoring of skin temperature can be a good approach in this regard which is currently used by some hospitals [40]. Wearable devices are considered as an efficient solution for this purpose. Many researchers have already proposed wearable devices for continuous body temperature monitoring which can be used for COVID-19 patients.

Song et al. [41] proposed a wearable system based on multiple artificial neural networks which monitors the body temperature very precisely with shorter reaction time. Liu et al. [42] proposed a wearable device as a physiological monitoring system that monitors body temperature, ECG, blood glucose, blood pressure, and some other physiological parameters. The device is very small in size, easy to use, and specially developed for home application which can be used for COVID-19 patients. During this pandemic, infants can also be infected by the COVID-19. Zakaria et al. [43] developed an IoT based body temperature monitoring, especially for infants. The device is very small in size, lightweight, and continuously monitors the body temperature and comfortably used by the baby. Another IoT based device named Health Companion using wearable computing was proposed by Kulkarni et al. [44] which monitors the temperature and pulse. This device aims to measure and collect different parameters of the human body, assist the users to monitor their physical condition, and facilitates the doctors to closely investigate the patients' ailments. This device can be used for fever tracking during illness. The device also alerts users as well as the clinical staff of sharp changes in temperature or high fever.

\section{Oxygen Saturation $\left(\mathrm{SpO}_{2}\right)$ Monitoring}

Respiratory illness of a patient can be assessed by measuring the level of blood oxygen saturation $\left(\mathrm{SpO}_{2}\right)$. It measures the percentage of hemoglobin saturated with oxygen which is an indication of the overall physical condition of the human body. $\mathrm{SpO}_{2}$ level of an overall healthy person is $95-100 \%$. It decreases if someone has respiratory distress [45] or any other health issues. This $\mathrm{SpO}_{2}$ is a crucial factor for monitoring the progression and acuteness of disease in COVID-19 infected patients. In addition, the resting $\mathrm{SpO}_{2}$ rate is significantly lower in patients who are in a severe stage.

Xue et al. [46] developed a wearable device that continuously monitors $\mathrm{S}_{\mathrm{p}} \mathrm{O}_{2}$ and body temperature in real-time. 
This device can be used for COVID-19 patients as its power consumption is very low and compact in design. A wearable device for Heart Rate Variability (HRV) and $\mathrm{SpO}_{2}$ estimation was proposed by Jarchi et al. [47] which used commercial wrist-worn pulse oximeter for achieving accurate results. Son et al. [48] developed a light reflection based wearable $\mathrm{SpO}_{2}$ measurement device for real-time monitoring. The device has small dimensions, accessible measurements, location tracking, and IoT support. Using the device, doctors can monitor the level of $\mathrm{SpO}_{2}$ of COVID-19 patients remotely. To measure the $\mathrm{SpO}_{2}$ of the patients experiencing obstructive sleep apnea (OSA), a telemedicine system was proposed by Rostami et al. [49]. The system allows realtime monitoring of the $\mathrm{SpO}_{2}$ level for the detection of apnea episodes in patients with OSA and helps them to track their health conditions. This telemedicine system can be very helpful for remote monitoring of the $\mathrm{SpO}_{2}$ level of COVID19 patients. In addition, Oxitone $1000 \mathrm{M}$ can be used for this purpose as it is the world's first FDA-approved wristsensor pulse oximetry monitor with high accuracy. The $\mathrm{SpO}_{2}$ measurement error rate for this device is within 3\% [50]. The device can also be worn on the different places of the body for example on the head or in the chest area.

\section{Respiratory Support Systems}

There are many assistive respiratory support systems [51] that are used to assist COVID-19 patients in their recovery process. The systems that are developed based on wearable technology for the respiration support of COVID-19 patients are outlined as follows.

\section{Ventilators as Respiratory Support}

Open source positive pressure ventilation device (OSPPVD) was developed in response to the shortage of ventilation capacity in hospitals for COVID-19 patients [52]. The OSPPVD assistive respiratory support system was designed in accordance with a health care professional descriptions and observation of COVID-19 infection rather than recreating existing technologies [53]. Most of the assistive breathing support systems for COVID-19 patients are very expensive. Hence, in response to this expensiveness of the systems, a preliminary investigation design for easy development, simple, innovative, and portable ventilator for COVID-19 patients was carried out in the study of [54]. The proposed ventilator would be developed in accordance with proper medical standards such as IEC 62304, ISO 5367, and ISO 80601 , and the system will facilitate the monitoring of expiratory/inspiratory ratio of COVID-19 patients via an LCD screen.

\section{CPAP Devices for Breathing Assistant}

The guidelines for the management of COVID-19 patients with respiratory failure are the use of continuous positive airway pressure (CPAP) and non-invasive ventilation (NIV) assistive respiratory support systems; provided appropriate personal protective equipment is worn. The CPAP and NIV devices have the potential to minimize the risk of airborne transmission from COVID-19 patients. According to [55], CPAP provides the application of a stable level of positive airway pressure throughout the entire respiratory cycle. The Formula One Company in collaboration with mechanical engineers from the University College London and clinicians at College London Hospital produced CPAP assistive respiratory support systems for COVID-19 patients which can easily be reproduced [56]. The system has already been approved by the medicines and health product regularly agency and it has been widely used for COVID-19 patients in Italy and China, respectively. The system is very effective while being less invasive and does not require healthcare workers or intensive monitoring because patients can be weaned off and put the bank on again if needed [56]. Nishkantha et al. [57] recommended the use of the helmet device for CPAP and pressure support ventilation (PSV) which are also respiratory support systems to limit the spread of the virus into the ambient air. A helmet is a reusable single interface made up of a plastic hood on a hard plastic ring with a multi-size silicon polyvinyl chloride soft collar to fit a wide range of neck's dimensions [58, 59]. An alternative Continuous Positive Airway Pressure system (ACPAP) assistive respiratory support system for COVID-19 was proposed to include an anesthesia reservoir bag to enable COVID-19 patients' spontaneous ventilation to be manually assisted and the system proved to be invaluable in generating larger breaths [60]. The ACPAP respiratory support system was developed by engineers from the Innovation Department of Hospital Sant Joan de Deu, Spain supported by researchers who developed a CPAP respiratory support system with positive end-expiratory pressure (PEEP) valve and a Venturi connector fitted to a facial snorkel interface [61]. The system offers an alternative frontal interface which reduces droplet dispersion that reduces the risk of infection to health workers.

\section{Oxygen Therapy for Respiration}

High flow nasal cannula (HFNC) is one of the respiratory support systems that support patients infected with COVID-19. COVID-19 infected patients were successfully discharged from the negative pressure intensive care unit (ICU) after treatment with HFNC respiratory support system [62]. HFNC respiratory support system allows COVID-19 patients to turn into the prone position three times a day, thus 
a manoeuvre that helps the patients in improving oxygenation. Non-invasive ventilation (NIV) and high flow nasal oxygen (HFO) breathing assistants have been used to manage acute hypoxemic respiratory failure caused by COVID$19[63,64]$.

\section{Discussions}

The unparalleled severity and exponential speed at which COVID-19 pandemic is spreading among humans have indeed taken modern healthcare systems around the world by surprise. The pandemic has exposed the ingenuity, importance, resilience, and selflessness of healthcare and essential workers worldwide. Sadly, healthcare workers are also more exposed and prone to coronavirus than anybody else and have one of the highest mortality rates. More than ever, we need the combined help of wearable technologies, telemedicine systems, medical robotic systems, diagnostic and AI monitoring systems in our war against the coronavirus.

Wearable symptoms monitoring systems can help to reduce the spread of coronavirus by detecting both individual infections and geographic coronavirus hot spots. They can also work as an immediate layer of protection between healthcare workers and infected patients. As smartphones and smartwatches are very common devices nowadays, they can be used as both sensors and IoT gateways towards mass health monitoring. Especially, smartwatch or wrist-worn device based $\mathrm{SpO}_{2}$ monitoring and heath rate monitoring systems can be used as early warning systems for coronavirus infections in a community $[47,48,50]$. Such systems would also be more suitable for widespread adoption due to their availability and lack of additional hardware modifications. While temperature monitoring systems are very useful for early monitoring of coronavirus, their effectiveness can be increased by pairing them with other monitoring systems such as respiratory rate monitoring systems, heart rate monitoring systems, $\mathrm{SpO}_{2}$ monitoring systems, etc. It is very difficult to combine all the symptoms monitoring systems in a combined system due to their vastly different sensing technology and hardware requirements. Therefore, more effort should be put on the development of symptoms monitoring systems with increasing sensitivity rates for early detection of a large number of COVID-19 infected patients. It should be noted that most of the crucial medical detection systems employ a two-test verification process $[65,66]$. The first test maximizes sensitivity, while the second test maximizes specificity to identify actual patients. The symptoms monitoring systems can also be combined in such ways to identify all potential coronavirus patients.

Assistive respiratory support systems have been widely used for COVID-19 patients. However, they are comparatively expensive, poses the risk of infection to workers and some are not user friendly such as NIV, HFO, and CPAP breathing assistants. Without appropriate personal protective and good fitting equipment, these devices increase the risk of airborne transmission from COVID-19 patients. Open source respiratory support systems are also available such as OSPPV which is inexpensive and developed in response to the shortage of ventilation capacity in most of the hospital around the world especially in developing nations. Likewise, some preliminary investigations were carried to develop simple, innovative, and portable ventilators for COVID-19 patients such as the work in [54]. Assistive respiratory support systems such as the CPAP [56] are less invasive and do not require intensive care from health workers. These systems also work on a need basis as patients can be easily put off the device when they recover and re-introduced if necessary. Ventilators are still very high in demand due to various cost and production bottlenecks. Production of such systems is further bottlenecked due to the limited number of factory workers amidst the pandemic. Thus, research should be focused on not only developing cheap alternatives to ventilators but also on faster scalable production systems.

Telemedicine, IoT, and IoMT systems can play a vital role in minimizing the risks of healthcare workers as they don't require proximity to patients. However, the burning issues such as motion artifact, power consumption, and real-time processing need to be addressed before these systems can be utilized to their full potential. The improvement of such wearable remote monitoring systems would also facilitate the implementation of cost-effective and timely healthcare solutions that span the entirety of the management process of COVID-19 patients from early warning systems to prevention, diagnosis, treatment, and rehabilitation.

In the future, research can be focused on developing flexible and stretchable sensing solutions for prolonged periods of use and continuous monitoring. Intelligent fabrics employing wearable sensors should also be developed as it helps to monitor all the vital symptoms regarding coronavirus. The pandemic is also affecting the mental health of the population. So, emotion-aware abilities can be integrated into IoMT solutions to monitor the mental health patients and provide necessary personalized assistance whenever necessary.

The huge amounts of data from wearable sensors can be further utilized if they are synced centrally. Centralized data syncing and data analysis will play a major role in quickly identifying affected regions and help to lower the spread of the disease. This data can be used to train efficient AI solutions that monitor and predict possible outbreaks, anomalies, and exacerbations. However, the largest impediment towards developing such systems are the issues of data privacy, data sharing, and miss-use of data. The problem is further compounded by complex communication protocols, malicious attacks, outdated infrastructure, etc. Ethical and responsible 
use of these kinds of sensitive data would alleviate some of the concerns related to mass monitoring solutions such as contact tracing applications.

Also, there is a considerable social stigma towards coronavirus patients or people who are suspected of being coronavirus infected. Mass media campaigns can be organized in the future to raise public awareness regarding these issues. Further research should also be focused on creating patientoriented systems. The developed systems should be tested on metrics such as user satisfaction, patient outcome, etc.

\section{Conclusion}

An unprecedented disaster such as the coronavirus pandemic forces us to re-think the role of technology in the operation of healthcare services. COVID-19 pandemic serves as a catalyst to prompt discussions about the importance of publicly or privately funded research well ahead of an unexpected pandemic that might happen in the future and the innovative usage of existing technology to overcome the limitations of the current management scheme of healthcare systems. Although wearable technologies demonstrate tremendous potential in dealing with infectious diseases such as the novel coronavirus, the aforementioned limitations hinder widespread adoption. While limitations such as privacy concerns require immediate attention, there is no doubt that wearable technologies can not only work as an early warning system but also as life-saving devices. When we emerge out of this crisis, it is of paramount importance that we should continue our undivided attention and research into these paradigm changes and technologies.

Funding No funding sources.

\section{Compliance with Ethical Standards}

Conflict of interest On behalf of all authors, the corresponding author states that there is no conflict of interest.

\section{References}

1. Guan W, Ni Z, Hu Y, Liang W, Ou C, He J, Liu L, Shan H, Lei C, Hui DSC, Du B, Li L, Zeng G, Yuen K-Y, Chen R, Tang C, Wang T, Chen P, Xiang J, Li S, Wang J, Liang Z, Peng Y, Wei L, Liu Y, Hu Y, Peng P, Wang J, Liu J, Chen Z, Li G, Zheng Z, Qiu S, Luo $\mathrm{J}$, Ye C, Zhu S, Zhong N. Clinical characteristics of coronavirus disease 2019 in China. N Engl J Med. 2020;382:1708-20. https ://doi.org/10.1056/NEJMoa2002032.

2. WHO COVID. [Online]. Available: https://covid19.who.int/. Accessed 2 Sep 2020

3. Ksiazek TG, Erdman D, Goldsmith CS, Zaki SR, Peret T, Emery S, Tong S, Urbani C, Comer JA, Lim W, Rollin PE, Dowell SF, Ling A-E, Humphrey CD, Shieh W-J, Guarner J, Paddock
CD, Rota P, Fields B, DeRisi J, Yang J-Y, Cox N, Hughes JM, LeDuc JW, Bellini WJ, Anderson LJ. A novel coronavirus associated with severe acute respiratory syndrome. N Engl J Med. 2003;348:1953-66. https://doi.org/10.1056/NEJMoa030781.

4. Rabi FA, Al Zoubi MS, Kasasbeh GA, Salameh DM, Al-Nasser AD. SARS-CoV-2 and coronavirus disease 2019: what we know so far. Pathogens. 2020;9:231. https://doi.org/10.3390/pathogens9 030231.

5. Peiris J, Lai S, Poon L, Guan Y, Yam L, Lim W, Nicholls J, Yee W, Yan W, Cheung M, Cheng V, Chan K, Tsang D, Yung R, $\mathrm{Ng} \mathrm{T}$, Yuen K. Coronavirus as a possible cause of severe acute respiratory syndrome. Lancet. 2003;361:1319-25. https://doi. org/10.1016/S0140-6736(03)13077-2.

6. Tang B, Bragazzi NL, Li Q, Tang S, Xiao Y, Wu J. An updated estimation of the risk of transmission of the novel coronavirus (2019-nCov). Infect Dis Model. 2020;5:248-55. https://doi. org/10.1016/j.idm.2020.02.001.

7. Liu T, Hu J, Xiao J, He G, Kang M, Rong Z, Lin L, Zhong H, Huang Q, Deng A, Zeng W, Tan X, Zeng S, Zhu Z, Li J, Gong D, Wan D, Chen S, Guo L, Li Y, Sun L, Liang W, Song T, He J, Ma W. Time-varying transmission dynamics of novel coronavirus pneumonia in China. BioRxiv. 2020. https://doi. org/10.1101/2020.01.25.919787.

8. Yue T, Fan Z, Fan B, Du Z, Wilson JP, Yin X, Zhao N, Wang Y, Zhou C. A new approach to modeling the fade-out threshold of coronavirus disease. Sci Bull. 2020;65:1225-7. https://doi. org/10.1016/j.scib.2020.04.016.

9. Ayon SI, Islam MM, Hossain MR (2020) Coronary artery heart disease prediction: a comparative study of computational intelligence techniques. IETE J Res 1-20. https://doi.org/10.1080/03772 063.2020 .1713916

10. Islam Ayon S, Milon Islam M. Diabetes prediction: a deep learning approach. Int J Inf Eng Electron Bus. 2019;11:21-7. https:// doi.org/10.5815/ijieeb.2019.02.03.

11. Islam MM, Haque MR, Iqbal H, Hasan MM, Hasan M, Kabir MN. Breast cancer prediction: a comparative study using machine learning techniques. SN Comput Sci. 2020;1:290. https://doi. org/10.1007/s42979-020-00305-w.

12. Islam MM, Iqbal H, Haque MR, Hasan MK (2017) Prediction of breast cancer using support vector machine and K-Nearest neighbors. In: 2017 IEEE Region 10 Humanitarian Technology Conference (R10-HTC). IEEE, pp. 226-229

13. Hasan MK, Islam MM, Hashem MMA (2016) Mathematical model development to detect breast cancer using multigene genetic programming. In: 2016 th International Conference on Informatics, Electronics and Vision (ICIEV). IEEE, pp. 574-579

14. Haque MR, Islam MM, Iqbal H, Reza MS, Hasan MK (2018) Performance evaluation of random forests and artificial neural networks for the classification of liver disorder. In: 2018 International Conference on Computer, Communication, Chemical, Material and Electronic Engineering (IC4ME2). IEEE, pp. 1-5

15. Vaishya R, Javaid M, Khan IH, Haleem A. Artificial intelligence (AI) applications for COVID-19 pandemic. Diabetes Metab Syndr Clin Res Rev. 2020;14:337-9. https://doi.org/10.1016/j. dsx.2020.04.012.

16. Fong ZV, Qadan M, McKinney R, Griggs CL, Shah PC, Buyske J, Sachdeva AK, Callery MP, Altieri MS. Practical implications of novel coronavirus COVID-19 on hospital operations, board certification, and medical education in surgery in the USA. J Gastrointest Surg. 2020;24:1232-6. https://doi.org/10.1007/s1160 5-020-04596-5.

17. Islam MM, Karray F, Alhajj R, Zeng J (2020) A review on deep learning techniques for the diagnosis of novel coronavirus (COVID-19). 1-18. https://arxiv.org/abs/2008.04815

18. Islam MZ, Islam MM, Asraf A. A combined deep CNN-LSTM network for the detection of novel coronavirus (COVID-19) using 
X-ray images. Informat Med Unlocked. 2020;20:100412. https:// doi.org/10.1101/2020.06.18.20134718.

19. Muhammad LJ, Islam MM, Usman SS, Ayon SI. Predictive data mining models for novel coronavirus (COVID-19) infected patients' recovery. SN Comput Sci. 2020;1:206. https://doi. org/10.1007/s42979-020-00216-w.

20. Islam MM, Islam MZ, Asraf A, Ding W (2020) Diagnosis of COVID-19 from X-rays using combined CNNRNN architecture with transfer learning. 1-15. https://doi. org/10.1101/2020.08.24.20181339

21. Ding X-R, Clifton D, JI N, Lovell NH, Bonato P, Chen W, Yu X, Xue Z, Xiang T, Long X, Xu K, Jiang X, Wang Q, Yin B, Feng G, Zhang Y (2020) Wearable sensing and telehealth technology with potential applications in the coronavirus pandemic. IEEE Rev Biomed Eng 1-1. https://doi.org/10.1109/RBME.2020.29928 38

22. Rahaman A, Islam M, Islam M, Sadi M, Nooruddin S. Developing IoT based smart health monitoring systems: a review. Rev Intell Artif. 2019;33:435-40. https://doi.org/10.18280/ria.330605.

23. Islam MM, Rahaman A, Islam MR. Development of smart healthcare monitoring system in IoT environment. SN Comput Sci. 2020;1:185. https://doi.org/10.1007/s42979-020-00195-y.

24. Liu Y, Yan L-M, Wan L, Xiang T-X, Le A, Liu J-M, Peiris M, Poon LLM, Zhang W. Viral dynamics in mild and severe cases of COVID-19. Lancet Infect Dis. 2020;20:656-7. https://doi. org/10.1016/S1473-3099(20)30232-2.

25. Arons MM, Hatfield KM, Reddy SC, Kimball A, James A, Jacobs JR, Taylor J, Spicer K, Bardossy AC, Oakley LP, Tanwar S, Dyal JW, Harney J, Chisty Z, Bell JM, Methner M, Paul P, Carlson CM, McLaughlin HP, Thornburg N, Tong S, Tamin A, Tao Y, Uehara A, Harcourt J, Clark S, Brostrom-Smith C, Page LC, Kay M, Lewis J, Montgomery P, Stone ND, Clark TA, Honein MA, Duchin JS, Jernigan JA. Presymptomatic SARS-CoV-2 infections and transmission in a skilled nursing facility. N Engl J Med. 2020;382:2081-90. https://doi.org/10.1056/NEJMoa2008457.

26. Madjid M, Safavi-Naeini P, Solomon SD, Vardeny O. Potential effects of coronaviruses on the cardiovascular system. JAMA Cardiol. 2020;5:831. https://doi.org/10.1001/jamacardio.2020.1286.

27. Capodilupo $\mathrm{E}(2020)$ The importance of respiratory rate tracking during the COVID-19 pandemic. [Online]. Available: https:// www.whoop.com/the-locker/respiratoryrate-tracking-coronaviru s/. Accessed 4 April 2020

28. Huang C, Wang Y, Li X, Ren L, Zhao J, Hu Y, Zhang L, Fan G, Xu J, Gu X, Cheng Z, Yu T, Xia J, Wei Y, Wu W, Xie X, Yin W, Li H, Liu M, Xiao Y, Gao H, Guo L, Xie J, Wang G, Jiang R, Gao Z, Jin Q, Wang J, Cao B. Clinical features of patients infected with 2019 novel coronavirus in Wuhan, China. Lancet. 2020;395:497506. https://doi.org/10.1016/S0140-6736(20)30183-5.

29. Liu G-Z, Guo Y-W, Zhu Q-S, Huang B-Y, Wang L. Estimation of respiration rate from three-dimensional acceleration data based on body sensor network. Telemed e-Health. 2011;17:705-11. https:// doi.org/10.1089/tmj.2011.0022.

30. Chu M, Nguyen T, Pandey V, Zhou Y, Pham HN, Bar-Yoseph R, Radom-Aizik S, Jain R, Cooper DM, Khine M. Respiration rate and volume measurements using wearable strain sensors. NPJ Digit Med. 2019;2:8. https://doi.org/10.1038/s41746-019-0083-3.

31. Liu Y, Zhao L, Avila R, Yiu C, Wong T, Chan Y, Yao K, Li D, Zhang Y, Li W, Xie Z, Yu X. Epidermal electronics for respiration monitoring via thermo-sensitive measuring. Mater Today Phys. 2020;13:100199. https://doi.org/10.1016/j.mtphys.2020.100199.

32. Dai J, Zhao H, Lin X, Liu S, Liu Y, Liu X, Fei T, Zhang T. Ultrafast response polyelectrolyte humidity sensor for respiration monitoring. ACS Appl Mater Interfaces. 2019;11:6483-90. https://doi. org/10.1021/acsami.8b18904.

33. Huang Y Hui, Meng S Jun, Zhang Y, Wu S Sheng, Zhang Y, Zhang Y Wei, Ye Y Xiang, Wei Q Feng, Zhao N Gui, Jiang J
Ping, Ji X Ying, Zhou C Xia, Zheng C, Zhang W, Xie L Zhong, Hu Y Chao, He J Quan, Chen J, Wang W Yue, Zhang C Hua, Cao L, Xu W, Lei Y, Jian Z Hua, Hu W Ping, Qin W Juan, Wang W Yu, He Y Long, Xiao H, Zheng X Fang, Hu YQ, Pan WS, Cai J Feng (2020) The respiratory sound features of COVID-19 patients fill gaps between clinical data and screening methods

34. Charlton PH, Birrenkott DA, Bonnici T, Pimentel MAF, Johnson AEW, Alastruey J, Tarassenko L, Watkinson PJ, Beale R, Clifton DA. Breathing rate estimation from the electrocardiogram and photoplethysmogram: a review. IEEE Rev Biomed Eng. 2018;11:2-20. https://doi.org/10.1109/RBME.2017.27636 81.

35. Chen C, Yan JT, Zhou N, Zhao JP, Wang DW. Analysis of myocardial injury in patients with COVID-19 and association between concomitant cardiovascular diseases and severity of COVID19. Zhonghua Xin Xue Guan Bing Za Zhi. 2020. https://doi. org/10.3760/cma.j.cn112148-20200225-00123.

36. Quy VN, Xuan Duy DT, Kien DT, Tu VH, Sun Q, Roy VAL, Pham V-T, Dao TT (2019) Wearable device for monitoring heart rate based on low-cost piezoresistive sensor. In: 2019 8th International Conference on Modern Circuits and Systems Technologies (MOCAST). IEEE, pp. 1-4

37. Shahshahani A, Bhadra S, Zilic Z (2018) A piezo transducer based flexible hybrid sensor for health monitoring. In: 2018 International Flexible Electronics Technology Conference (IFETC). IEEE, pp. 1-2

38. Tamilselvi V, Sribalaji S, Vigneshwaran P, Vinu P, GeethaRamani J (2020) IoT based health monitoring system. In: 2020 6th International Conference on Advanced Computing and Communication Systems (ICACCS). IEEE, pp. 386-389

39. Banerjee SRS. Design of a photo plethysmography based pulse rate detector. Int J Rec Trends Eng Res. 2016;2:302-6.

40. News. Best Baby Digital Thermometer: TempTraq. (2020). [Online]. Available: https://www.temptraq.com/News/University -Hospitalsexpands-use-of-TempTraq\%C2\%AE-syst. Accessed 3 May 2020

41. Song C, Zeng P, Wang Z, Zhao H, Yu H. Wearable continuous body temperature measurement using multiple artificial neural networks. IEEE Trans Ind Inf. 2018;14:4395-406. https://doi. org/10.1109/TII.2018.2793905.

42. Liu B, Zhang Y, Liu Z (2008) Wearable monitoring system with multiple physiological parameters. In: 2008 5th International Summer School and Symposium on Medical Devices and Biosensors. IEEE, pp. 268-271

43. Zakaria NA, Mohd Saleh FNB, Razak MAA (2018) IoT (internet of things) based infant body temperature monitoring. In: 2018 2nd International Conference on BioSignal Analysis, Processing and Systems (ICBAPS). IEEE, pp. 148-153

44. Kulkarni C, Karhade H, Gupta S, Bhende P, Bhandare S (2016) Health companion device using IoT and wearable computing. In: 2016 International Conference on Internet of Things and Applications (IOTA). IEEE, pp. 152-156

45. WHO (2020) Algorithm for COVID-19 triage and referral: patient triage and referral for resource-limited settings during community transmission. https://apps.who.int/iris/handle/10665/33191 5. Accessed 3 May 2020

46. Xue J, Huang Y, Du X, Wu X, Wu K, Zeng W, Xi Y, Chen Y, Zhao $\mathrm{Y}$ (2015) Design of a wearable device for monitoring $\mathrm{SpO}_{2}$ continuously. In: 2015 IEEE 12th Intl Conf on Ubiquitous Intelligence and Computing and 2015 IEEE 12th Intl Conf on Autonomic and Trusted Computing and 2015 IEEE 15th Intl Conf on Scalable Computing and Communications and Its Associated Workshops (UIC-ATC-ScalCom). IEEE, pp. 1253-1257

47. Jarchi D, Salvi D, Velardo C, Mahdi A, Tarassenko L, Clifton DA (2018) Estimation of HRV and $\mathrm{SpO}_{2}$ from wrist-worn commercial sensors for clinical settings. In: 2018 IEEE 15th International 
Conference on Wearable and Implantable Body Sensor Networks (BSN). IEEE, pp. 144-147

48. Phuoc Son L, Thi Anh Thu N, Trung Kien N (2017) Design an IoT wrist-device for $\mathrm{SpO}_{2}$ measurement. In: 2017 International Conference on Advanced Technologies for Communications (ATC). IEEE, pp. 144-149

49. Rostami M, Janghorbani A (2014) Design and implementation of telemedicine system for $\mathrm{SpO}_{2}$ monitoring. In: 2014 22nd Iranian Conference on Electrical Engineering (ICEE). IEEE, pp. 1945-1949

50. Oxitone 1000M-World's First FDA-cleared Wrist-Sensor Pulse Oximetry Monitor. [Online]. Available: https://www.oxitone.com/ oxitone- $1000 \mathrm{~m} /$. Accessed 15 July 2020

51. Islam MM, Ullah SMA, Mahmud S, Raju SMTU. Breathing aid devices to support novel coronavirus (COVID-19) infected patients. SN Comput Sci. 2020;1:274. https://doi.org/10.1007/ s42979-020-00300-1.

52. Ahmad Faryami CAH (2020) Open source 3D printed ventilation device. https://doi.org/10.1101/2020.05.21.108043

53. Sorbello M, El-Boghdadly K, Di Giacinto I, Cataldo R, Esposito C, Falcetta S, Merli G, Cortese G, Corso RM, Bressan F, Pintaudi S, Greif R, Donati A, Petrini F. The Italian coronavirus disease 2019 outbreak: recommendations from clinical practice. Anaesthesia. 2020;75:724-32. https://doi.org/10.1111/anae.15049.

54. El Majid B, El Hammoumi A, Motahhir S, Lebbadi A, El Ghzizal A. Preliminary design of an innovative, simple, and easy-to-build portable ventilator for COVID-19 patients. Euro-Mediterr J Environ Integr. 2020;5:23. https://doi.org/10.1007/s41207-020-00163 -1 .

55. Longhini F, Bruni A, Garofalo E, Navalesi P, Grasselli G, Cosentini R, Foti G, Mattei A, Ippolito M, Accurso G, Vitale F, Cortegiani A, Gregoretti C. Helmet continuous positive airway pressure and prone positioning: a proposal for an early management of COVID-19 patients. Pulmonology. 2020;26:186-91. https://doi. org/10.1016/j.pulmoe.2020.04.014.

56. Mahase E (2020) Covid-19: Mercedes F1 to provide breathing aid as alternative to ventilator. BMJ m1294. https://doi.org/10.1136/ bmj.m1294

57. Arulkumaran N, Brealey D, Howell D, Singer M. Use of noninvasive ventilation for patients with COVID-19: a cause for concern? Lancet Respir Med. 2020;8:e45. https://doi.org/10.1016/ S2213-2600(20)30181-8.

58. Lucchini A, Giani M, Isgrò S, Rona R, Foti G. The "helmet bundle" in COVID-19 patients undergoing noninvasive ventilation. Intensive Crit Care Nurs. 2020;58:102859. https:// doi.org/10.1016/j.iccn.2020.102859.

59. Cabrini L, Landoni G, Zangrillo A. Minimise nosocomial spread of 2019-nCoV when treating acute respiratory failure. Lancet. 2020;395:685. https://doi.org/10.1016/S0140-6736(20)30359-7.

60. Pfitzner J, Maddern GJ, Reid J. An alternative continuous positive airway pressure system for COVID-19 patients. Br J Anaesth. 2020;125:e310-e313313. https://doi.org/10.1016/j. bja.2020.05.035.

61. Pons-Òdena M, Valls A, Grifols J, Farré R, Cambra Lasosa FJ, Rubin BK. COVID-19 and respiratory support devices. Paediatr Respir Rev. 2020;35:61-3. https://doi.org/10.1016/j. prrv.2020.06.015.

62. Karamouzos V, Fligou F, Gogos C, Velissaris D (2020) High flow nasal cannula oxygen therapy in adults with COVID-19 respiratory failure. A case report. Monaldi Arch Chest Dis 90. https:// doi.org/10.4081/monaldi.2020.1323

63. Guan L, Zhou L, Le Grange JM, Zheng Z, Chen R. Non-invasive ventilation in the treatment of early hypoxemic respiratory failure caused by COVID-19: considering nasal CPAP as the first choice. Crit Care. 2020;24:333. https://doi.org/10.1186/s 1305 4-020-03054-7.

64. Frat J-P, Thille AW, Mercat A, Girault C, Ragot S, Perbet S, Prat G, Boulain T, Morawiec E, Cottereau A, Devaquet J, Nseir S, Razazi K, Mira J-P, Argaud L, Chakarian J-C, Ricard J-D, Wittebole X, Chevalier S, Herbland A, Fartoukh M, Constantin J-M, Tonnelier J-M, Pierrot M, Mathonnet A, Béduneau G, DelétageMétreau C, Richard J-CM, Brochard L, Robert R. High-flow oxygen through nasal cannula in acute hypoxemic respiratory failure. N Engl J Med. 2015;372:2185-96. https://doi.org/10.1056/ NEJMoa1503326.

65. Guthrie D, Kraemer HC. Evaluating medical tests: objective and quantitative guidelines. J Am Stat Assoc. 1992;87:1243. https:// doi.org/10.2307/2290671.

66. Qiu P. The statistical evaluation of medical tests for classification and prediction. J Am Stat Assoc. 2005;100:705-705. https://doi. org/10.1198/jasa.2005.s19.

Publisher's Note Springer Nature remains neutral with regard to jurisdictional claims in published maps and institutional affiliations. 